Session 2793

\title{
Using Streaming Media in the Classroom
}

\author{
James Patton, Electrical and Computer Engineering \\ Knud Hermansen, Civil Engineering Technology \\ University of Maine
}

\begin{abstract}
$\underline{\text { Abstract }}$
An interactive, CD-ROM based, audio/video presentation was produced that documents an investigation into the benefits, problems and impact of using internet technology to alter the traditional on-campus lecture delivery model. The questions explored included: What is the impact of students receiving "lecture" at home and participating in either individual or group study in class? What are the technical problems? How should the course be structured? What tools can be used? Can you or should you mix on-campus audiences with off-campus students? Is the technology ready? The extensive experience of several University of Maine faculty is drawn together in a Macromedia Director presentation to answer these questions and draw conclusions. The process of creating the Director presentation is discussed as well.
\end{abstract}

\section{Process}

We created a multimedia presentation that documents how faculty at the University of Maine are using streaming media in their classes. See Figure 1. We videotaped the remarks of seven faculty who have used the media in several different ways:

- Live streaming audio in which the professor is teaching from a home office

- Asynchronous audio/video. The audio lecture is prepared ahead of time and linked with a web page prepared with IT support - no live in-class students

- Minimum production value efforts. The preceding situation is contrasted to a situation where the faculty member has little support for creating content with high production value.

- Using streaming media to explore new paradigms for distributing education. We have begun to see signs of "franchise" relationships between Universities with recognized centers of excellence and universities with fewer resources taking advantage of the offerings of these centers. Technology makes it possible to "connect" them.

- Teleconferencing using compressed video over ISDN lines. The experience is nearly like the classroom, but student access is limited.

Findings

Some common myths are discussed:

- "You can save money, time, and allow faculty to teach larger classes." The faculty interviewed here all agree that the effort equals or exceeds that related to live, in-person courses.

- "You can simply expand the walls - bringing students from afar into your regular classroom." In the absence of substantial external support, this goal has still not been attained. Although 
the tools are getting easier to use, the technology commonly available to faculty is still not powerful enough to perform the tasks needed. A desired "ideal" system is described.

Issues and Problems discussed

- "When are your office hours?" The difficulty is that students believe on-line faculty are available at any time of the day.

- “Am I being taught by a real person?" The problem of on-line courses lacking the passion of in-person classes are discussed. Interaction involving some variation of a synchronous component is seen to be one solution.

- Around final exam time, "how did you say I log into this course?" On-line asynchronous courses tempt some students to put off all coursework until late in the semester. It's important to be clear about the course schedule and requirements.

- "Murphy's Law applied to the on-line classroom" If the delivery system is too complicated, faculty won't use it.

- "How will I ever find the time to teach this way?" The difference in lesson preparation time is discussed.

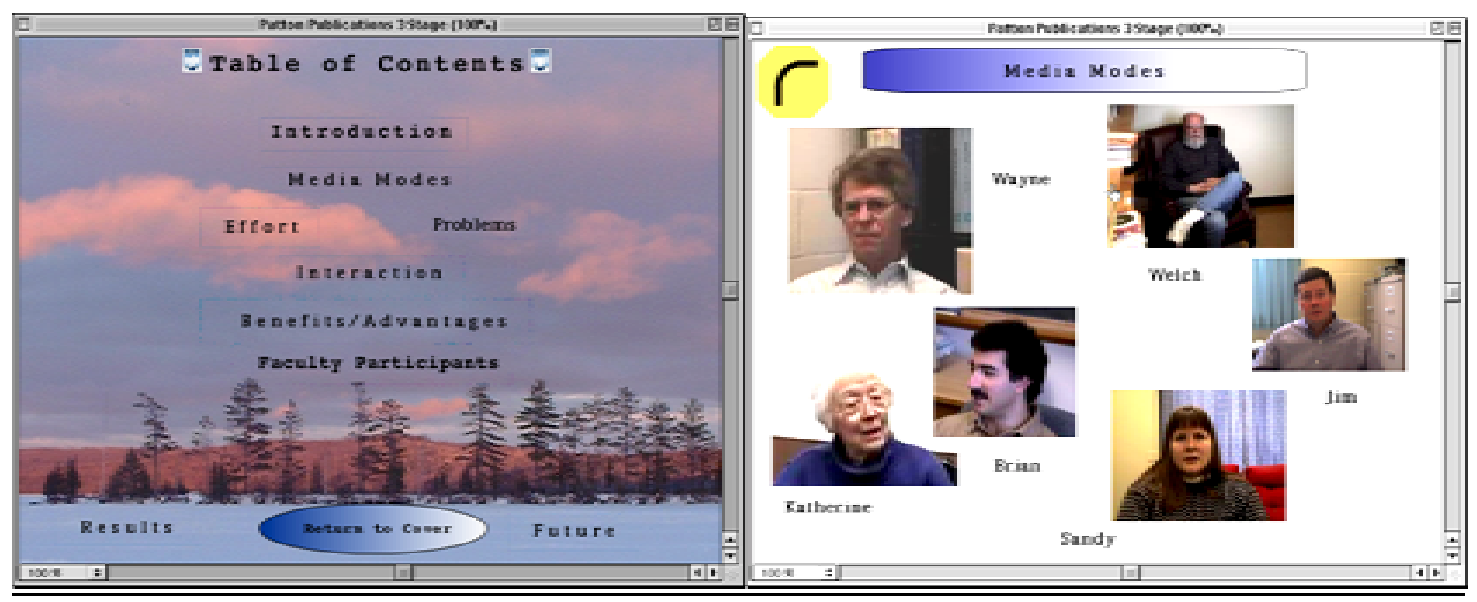

Figure 1 - Production Table of Contents and Media Modes topic area.

Benefits cited

- Less in-class lecture provides time for more interaction with the students.

- Fewer errors in well-prepared presentations

- Answers one criticism often levied against active or collaborative learning - "how will I get through my syllabus if I spend all my class time doing active learning?"

- Students appreciate the asynchronous nature of lecture - they learn when they're awake, not when we say they should be awake.

- Students can revisit lectures after attempting exercises.

- Course scheduling can be more flexible, knowing the course can be taken from anywhere at any time.

In summary, the production explains what works and what doesn't - both from a technological and pedagogical point-of-view. 
Though the authors are engineers and the initial target audience for this production was engineers, it was soon realized the majority of issues faculty face in streaming material is not unique to a particular discipline. Some issues unique to engineering or science are discussed. These issues usually involve the time and effort needed to prepare figure-intensive and equationintensive material. In addition, the use of asynchronous bulletin-board discussions are used less frequently in engineering courses.

\section{Production/ creation}

The exercise of creating this production was itself meaningful. Neither of the authors had any experience whatsoever in film editing or multimedia production. The major tools used were:

- a digital camcorder

- Macromedia Director for creating the interaction

- Final Cut Pro for editing the audio and video clips

- Media Cleaner Pro for compressing the audio/video into usable Quicktime movies

It was necessary to purchase a dedicated 45 GB hard drive to store the media generated in the project. A Windows or Mac version of the $\mathrm{CD}$ is available from the authors (patton@eece.maine.edu)

\section{Sampling of faculty remarks}

Wayne Ingalls has prepared thousands of Powerpoint slides accompanied by RealAudio narration. His courses are offered on-line as well as on-campus. For on-campus lectures, he uses web material to supplement his lectures, offering another learning mode for students. Students taking the course over the web are given solutions to homework problems, while oncampus students submit homework for grading and return. Wayne offers tips for dealing with massive amounts of email from students.

Welch Everman offers a live RealAudio lecture from his home office. During the lecture, he monitors a live chat window, where students actively participate. At times, the interaction has almost overwhelmed the chat server. His experience illustrates the value of a synchronous component to the learning experience. The interaction that Welch has achieved far exceeds the interaction he experienced in a live, large lecture, classroom format.

Sandy Caron has taken advantage of the medium to introduce role-playing in her teaching. Her multi-media lectures incorporate the use of audio/video and animation. The material is streamed over the internet. Sandy admits to being "technology challenged", while producing a course that students have said is the best they have ever taken, anywhere, in any format.

Katherine Musgrave is an emerita professor who speaks of the differences between on-line and in-class students. On-line students tend to be more diligent. However, they are more likely to drop out of the course. Her experience is reinforced by the other participating faculty.

Jim Patton speaks of the special effort required by engineering courses and the steps through which faculty progress in transitioning from live, in-class experience to live teleconferencing to asynchronous video recording to asynchronous media streaming. He speaks of a "dream system" that would allow fully-involved, interactive learning/teaching at a distance. 
Brian Roach describes the difficulties of dealing with a technology that is "not quite there" in terms of the material he would like to present. He also speaks of the difficulty of "connecting" with remote students and bringing a sense of passion for the subject material into a streamed class.

Jim Toner is the Director of Distance Education at the University of Maine. He remarks on trends in the offering of on-line courses. More and more on-campus students are choosing to take courses asynchronously in order to gain scheduling benefits. It is becoming harder and harder to distinguish between "distance" and "local" students.

\section{$\underline{\text { Conclusions }}$}

Streaming media is a useful tool in presenting material to students. Its effectiveness is dependent to a large extent on the faculty using it. There is often a direct correlation between effective classroom teaching and effective teaching using streaming media at a distance. Streaming media is not a method or substitute but rather a tool. Its ability to enhance teaching effectiveness is dependent on faculty familiarity, innovative use, and effectiveness in integration with other teaching/learning tools. Problems will be overcome with more sophisticated technology, faculty training, and increased familiarity and experience among students and faculty.

\section{Biographies}

\section{James Patton}

Dr. Patton has been at the University of Maine since 1991. He is currently serving as Chair of the Electrical and Computer Engineering Department. Prior to joining the University, Dr. Patton worked for General Electric Co. and Systems Control Inc. He is a registered Professional Engineer in the State of Maine, a Senior Member of the IEEE, and is a member of Tau Beta Pi.

Knud Hermansen

Dr. Hermansen is a professor in civil engineering technology at the University of Maine. He is an attorney, professional engineer, and professional land surveyor licensed in several states. His education includes a Ph.D. in Civil Engineering from the Pennsylvania State University and a J.D. (Doctorate in Law) from West Virginia University. 